\title{
Burden of adhesions in abdominal and pelvic surgery: systematic review and met-analysis
}

\author{
(c) (1) (8) OPEN ACCESS
}

\author{
Richard P G ten Broek PhD candidate ${ }^{1}$, Yama Issa PhD candidate ${ }^{1}$, Evert J P van Santbrink \\ gynaecologist $^{2}$, Nicole D Bouvy surgeon ${ }^{3}$, Roy F P M Kruitwagen gynaecologist ${ }^{4}$, Johannes Jeekel \\ surgeon $^{5}$, Erica A Bakkum gynaecologist ${ }^{6}$, Maroeska M Rovers senior epidemiologist ${ }^{7}$, Harry van \\ Goor surgeon ${ }^{1}$
}

\begin{abstract}
'Department of Surgery, Radboud University Nijmegen Medical Center, PO Box 9101, 6500 HB Nijmegen, Netherlands ; ${ }^{2}$ Department of Reproductive Medicine, Reinier de Graaf Group, Voorburg, Netherlands; ${ }^{3}$ Department of Surgery, Maastricht University Medical Centre, Maastricht, Netherlands; ${ }^{4}$ Department of Obstetrics and Gynaecology, and GROW—School for Oncology and Developmental Biology, Maastricht University Medical Centre, Maastricht, Netherlands; ${ }^{5}$ Department of Neuroscience, Erasmus Medical Center, Rotterdam, Netherlands.; ${ }^{6}$ Department of Obstetrics and Gynaecology, Onze Lieve Vrouwe Gasthuis Amsterdam, Netherlands; ${ }^{7}$ Departments of Operating Rooms and Health Evidence, Radboud University Nijmegen Medical Center, Nijmegen, Netherlands
\end{abstract}

\begin{abstract}
Objective To estimate the disease burden of the most important complications of postoperative abdominal adhesions: small bowel obstruction, difficulties at reoperation, infertility, and chronic pain. Design Systematic review and meta-analyses.

Data sources Searches of PubMed, Embase, and Central, from January 1990 to December 2012, without restrictions to publication status or language.

Study selection All types of studies reporting on the incidence of adhesion related complications were considered.

Data extraction and analysis The primary outcome was the incidence of adhesive small bowel obstruction in patients with a history of abdominal surgery. Secondary outcomes were the incidence of small bowel obstruction by any cause, difference in operative time, enterotomy during adhesiolysis, and pregnancy rate after abdominal surgery. Subgroup and sensitivity analyses were done to study the robustness of the results. A random effects model was used to account for heterogeneity between studies.

Results We identified 196 eligible papers. Heterogeneity was considerable for almost all meta-analyses. The origin of heterogeneity could not be explained by study design, study quality, publication date, anatomical site of operation, or operative technique. The incidence of small bowel obstruction by any cause after abdominal surgery was $9 \%$ (95\% confidence interval $7 \%$ to $10 \% ; I^{2}=99 \%$ ). the incidence of adhesive small bowel obstruction was $2 \%\left(2 \%\right.$ to $\left.3 \% ; I^{2}=93 \%\right)$; presence of adhesions was generally confirmed by emergent reoperation. In patients with a known cause of small bowel obstruction, adhesions were the
\end{abstract}

single most common cause $\left(56 \%, 49 \%\right.$ to $\left.64 \% ; I^{2}=96 \%\right)$. Operative time was prolonged by 15 minutes (95\% confidence interval 9.3 to 21.1 minutes; $I^{2}=85 \%$ ) in patients with previous surgery. Use of adhesiolysis resulted in a $6 \%\left(4 \%\right.$ to $\left.8 \% ; I^{2}=89 \%\right)$ incidence of iatrogenic bowel injury. The pregnancy rate after colorectal surgery in patients with inflammatory bowel disease was $50 \%$ ( $37 \%$ to $63 \%$; $\left.\right|^{2}=94 \%$ ), which was significantly lower than the pregnancy rate in medically treated patients $(82 \%, 70 \%$ to $94 \% ; I^{2}=97 \%$ ).

Conclusions This review provides detailed and systematically analysed knowledge of the disease burden of adhesions. Complications of postoperative adhesion formation are frequent, have a large negative effect on patients' health, and increase workload in clinical practice. The quantitative effects should be interpreted with caution owing to large heterogeneity.

Registration The review protocol was registered through PROSPERO (CRD42012003180).

\section{Introduction}

Postoperative adhesion formation is the most common complication of abdominal or pelvic surgery, which is frequently performed by general, vascular, and gynaecological surgeons and urologists. Unlike other postoperative complications, such as wound infection or anastomotic leakage, the consequences of adhesion formation comprise a lifelong risk for various clinical entities. ${ }^{1-6}$ Patients with adhesion related complications are often treated by specialists other than the surgeon who did the first operation. The first surgeon therefore remains unaware of the complication, which might explain the gross 
underestimation of adhesion related complications among surgeons and gynaecologists. ${ }^{7-9}$

Knowledge of complications is vital in surgical decision making, timely recognition of complications, and informing the patient properly before surgery. Adhesions may cause acute abdomen by bowel obstruction and female infertility, and patients may require reoperation. ${ }^{5-14}$ Lysis of adhesions is associated with a prolonged operative time and an increased risk of intraoperative and postoperative complications. ${ }^{514}$ Most of the epidemiological knowledge of adhesions has been derived from the extensive work of the Surgical and Clinical Adhesions Research (SCAR) Group. ${ }^{4-16}$ They, however, defined readmissions as a proxy for the effect of adhesions, which lacks detailed information on the effect of different adhesive complications. Data on adhesion related complications are reported incidentally, and different outcome measures have been used. However, when studied systematically, the studies published so far will provide a large body of evidence on the effect of adhesion formation.

In this systematic review with meta-analyses, we studied the incidence of the four most important complications of postoperative adhesion formation: small bowel obstruction, difficulties at repeated abdominal surgery, female infertility, and chronic pain. A more valid estimate of the disease burden of adhesions will increase the awareness of this complication, which can be used in counselling and clinical practice.

\section{Methods}

\section{Search}

Two researchers (RPGtB and YI) searched the Cochrane Central Register of Controlled Trials, PubMed, and Embase from January 1990 to December 2012, using the search terms for small bowel obstruction, incidence and morbidity of small bowel obstruction, female infertility, chronic pain, and history of abdominal surgery listed in the box. We additionally searched the reference lists of included studies, excluded studies, and previous reviews. We included studies irrespective of language or publication status. We carried out the review in accordance with a protocol that was registered in PROSPERO (CRD42012003180) after a first version of this paper was written but before the major revisions were done (web appendix A).

\section{Study selection}

We selected the studies in two rounds: firstly, on title and abstract, independently by two reviewers (RPGtB and YI); secondly, on full text, also independently by the same two reviewers, against pre-specified criteria. We included studies that reported on adhesion related complications after peritoneal surgery. We excluded case series with less than 10 patients and studies that did not include (trans)peritoneal abdominal surgery (for example, preperitoneal or retroperitoneal surgery). If more than one publication was available, we used either the most recent publication or the one with the most relevant information.

\section{Data extraction}

Two reviewers (RPGtB and YI) extracted and checked the data. From the relevant articles, we extracted information on study design, characteristics, number of participants, and outcomes reported.

The primary outcome of interest was the incidence of adhesive small bowel obstruction during follow-up after peritoneal surgery, which we defined as any episode of postoperative small bowel obstruction with the presence of adhesions confirmed during reoperation or by imaging after exclusion of other causes of bowel obstruction. Secondary outcomes of interest related to small bowel obstruction were incidence of postoperative small bowel obstruction by any cause, the cross sectional incidence of adhesions in all patients with postoperative small bowel obstruction, the number of reoperations for adhesive small bowel obstruction, mortality, and length of hospital stay related to adhesive small bowel obstruction.

Secondary outcomes related to complications during reoperation were the incidence of inadvertent enterotomy and the difference in operative time between patients with and without previous surgery. Secondary outcomes related to infertility were the pregnancy rate following surgery, the pregnancy rate compared before and after surgery, use of fertility treatment following surgery, and incidence of adhesions in patients evaluated for infertility after surgery. We excluded surgical studies on operations that directly affected fertility, such as hysterectomy, bilateral ovariectomy, and sterilisation. The secondary outcomes related to chronic pain were the incidence of chronic pain following surgery and the incidence of adhesions in patients evaluated for chronic pain.

\section{Risk of bias assessment}

Two reviewers (RPGtB and YI) independently determined the quality score of non-randomised studies and of subanalyses and retrospective analyses of randomised controlled trials according to the revised version of the Newcastle-Ottawa scale for cohort studies (www.ohri.ca/programs/clinical_epidemiology/oxford. $\mathrm{htm}$ ), with a maximum score of five stars. Five stars is considered high quality, three to four stars is considered intermediate quality, and one to two stars is considered low quality. We assessed publication bias of included studies with funnel plots.

\section{Data synthesis and analysis}

We plotted individual study estimates of incidences and proportions. We used the inverse variance method for pooling the incidences and to calculate the corresponding $95 \%$ confidence intervals. As recommended in the Cochrane handbook, we used $\mathrm{I}^{2}$ tests to measure heterogeneity. We defined an $\mathrm{I}^{2}$ value between $50 \%$ and $75 \%$ as substantial heterogeneity and an $\mathrm{I}^{2}$ value of $75 \%$ or above as considerable heterogeneity. ${ }^{17}$ As we expected heterogeneity between studies, we used a random effects meta-analysis for the primary analyses. Such a random effects meta-analysis model involves an assumption that the effects being estimated in the different studies are not identical but follow some distribution. ${ }^{17}$ If applicable, we made additional forest plots and calculated pooled odds ratios to compare incidences between subgroups (for example, laparoscopy versus laparotomy) and the various anatomical locations (general surgery, upper gastrointestinal tract, lower gastrointestinal tract, hepatobiliary and pancreatic surgery, abdominal wall surgery, gynaecological surgery, urological surgery, and paediatric surgery).

We did sensitivity analyses to study best and worst case scenarios for the missing values. In the best case scenario analyses, we assumed that all dropouts did not have an adhesion related outcome and that all female dropouts became pregnant. In the worst case scenario analyses, we assumed that all dropouts had adhesion related outcomes and none became pregnant. We also did sensitivity analyses on the effect of risk of bias, the effect of single studies, the effect of the study design (prospective versus retrospective cohort), and the time frame (up to 2000 and after 2000) on point estimates. 


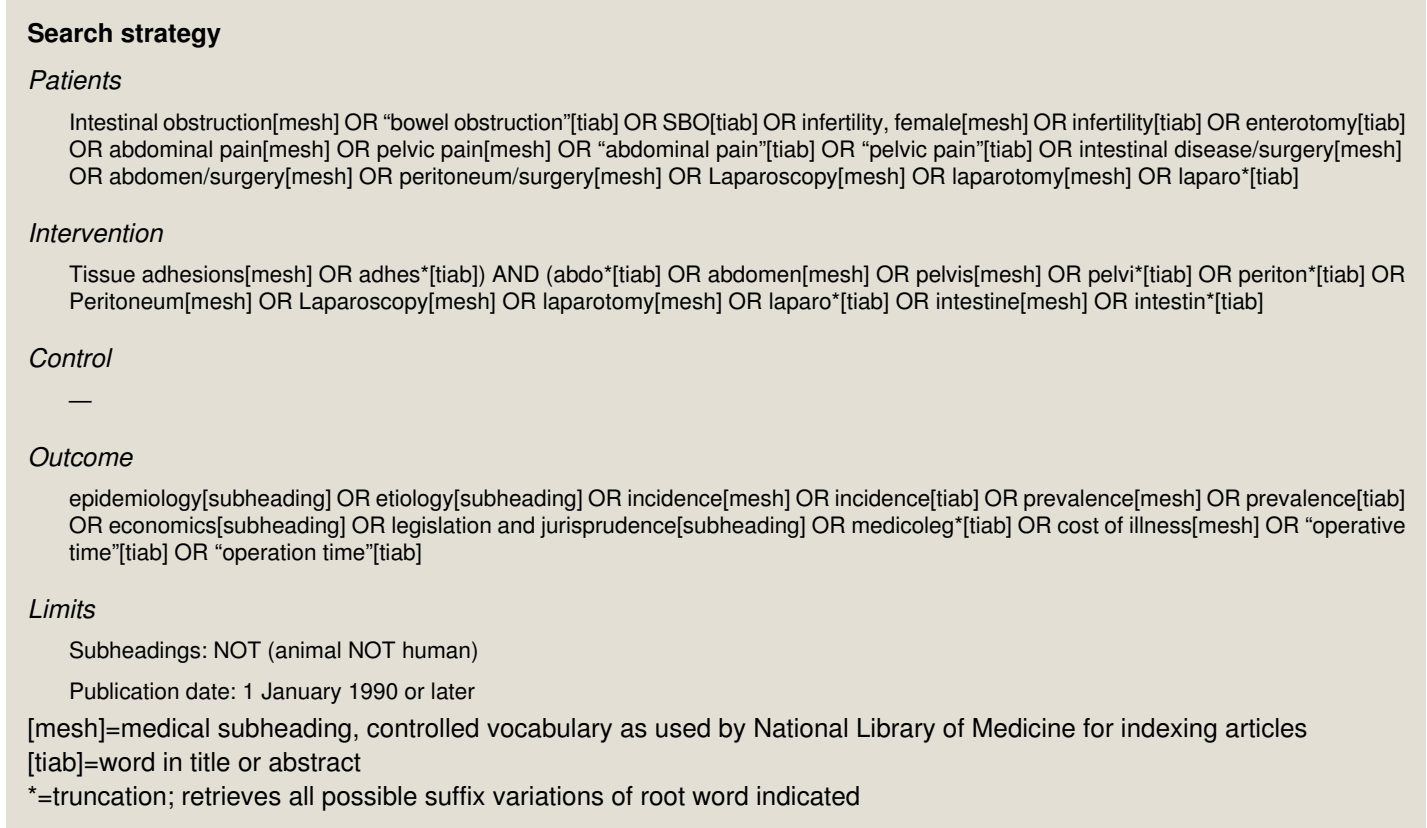

We used Review Manager (version 5.0) for all analyses. We followed both the Meta-analysis of Observational Studies in Epidemiology (MOOSE) and the Preferred Reporting Items for Systematic Reviews and Meta-Analyses (PRISMA) guidelines in reporting the results.

\section{Results \\ Search results}

Figure $1 \Downarrow$ shows the number of studies identified, reviewed, and selected and the reasons for exclusion. We retrieved 4152 unique citations, of which we considered 546 to be potentially eligible. Twenty three (4.2\%) papers could not be retrieved, and we excluded 327 because they reported on cohorts already included, no data on relevant endpoints were found, or the data could not be extracted for a cohort of patients with abdominal surgery in their history. We included 196 studies representing 150797 patients (web appendix B).

\section{Characteristics of included studies}

Studies were available for the analysis of small bowel obstruction $(\mathrm{n}=125)$, difficulties and complications at reoperation $(n=62)$, infertility $(n=11)$, and pain $(n=5)$. One hundred and sixty seven studies were done in adults and 27 in children; two studies included both children and adults. Forty one studies included patients with any surgical history, 11 included gynaecological surgery, 13 urological surgery, 79 lower gastrointestinal tract surgery, 21 upper gastrointestinal tract surgery, 16 hepatobiliary and pancreatic surgery, and 15 abdominal wall repair. Most of the included studies were judged to be of intermediate quality $(\mathrm{n}=125) ; 44$ had a low risk of bias, and 27 had a high risk of bias (web appendix C).

\section{Adhesive small bowel obstruction}

The incidence of small bowel obstruction following surgery was assessed in 92 studies. The incidence of postoperative small bowel obstruction, by any cause, was $9 \%$ (95\% confidence interval $7 \%$ to $10 \% ; \mathrm{I}^{2}=99 \%$ ) in 61 studies including 107949 patients. The incidence of adhesive small bowel obstruction was $2.4 \%\left(2.1 \%\right.$ to $\left.2.8 \% ; \mathrm{I}^{2}=93 \%\right)$ in 87 studies including 110 076 patients. In general, the presence of adhesions could be confirmed only in patients requiring reoperation. Not surprisingly, the incidence of reoperations for adhesive small bowel obstruction was comparable $(2.4 \%, 2.0 \%$ to $2.7 \%$; $\mathrm{I}^{2}=91 \%$ ). The cause of bowel obstruction could be established in 42 studies (including 5390 patients); adhesions seemed to be the most common cause of postoperative small bowel obstruction, accounting for $56 \%$ (49\% to $64 \% ; \mathrm{I}^{2}=96 \%$ ).

Best and worst case scenarios for the incidence of adhesive small bowel obstruction could be done using 67 studies (51 281 patients, of whom 3725 (7.3\%) were lost to follow-up). In the best case scenario, assuming all patients lost to follow-up did not develop adhesive small bowel obstruction, the incidence was $2.5 \%\left(2.0 \%\right.$ to $\left.2.9 \% ; \mathrm{I}^{2}=92 \%\right)$. In the worst case scenario, assuming all patients lost to follow-up developed adhesive small bowel obstruction, the incidence was $11.7 \%$ (10.1\% to $13.2 \%$; $\left.\mathrm{I}^{2}=99 \%\right)$. The incidence of postoperative small bowel obstruction by any cause was $9 \%\left(7 \%\right.$ to $\left.11 \% ; \mathrm{I}^{2}=99 \%\right)$ in the best case scenario and $15 \%\left(12 \%\right.$ to $\left.18 \% ; \mathrm{I}^{2}=99 \%\right)$ in the worst case scenario.

The incidence of adhesive small bowel obstruction depended on the anatomical location of previous surgery (fig $2 \Downarrow \Downarrow$ ). The incidence was highest in paediatric surgery $(4.2 \%, 2.8 \%$ to $\left.5.5 \% ; \mathrm{I}^{2}=86 \%\right)$ and in lower gastrointestinal tract surgery $(3.2 \%$, $2.6 \%$ to $\left.3.8 \% ; \mathrm{I}^{2}=84 \%\right)$. The incidence was lowest after abdominal wall surgery $\left(0.5 \%, 0.0 \%\right.$ to $\left.0.9 \% ; \mathrm{I}^{2}=0 \%\right)$, upper gastrointestinal tract surgery $\left(1.2 \%, 0.8 \%\right.$ to $\left.1.6 \% ; \mathrm{I}^{2}=80 \%\right)$, and urological surgery $\left(1.5 \%, 0.1 \%\right.$ to $\left.3.0 \% ; \mathrm{I}^{2}=67 \%\right)$. Similar trends were seen for the incidence of postoperative small bowel obstruction by any cause (web appendix D).

The incidence of adhesive small bowel obstruction was significantly lower in 29 laparoscopic cohorts $(1.4 \%, 1.0 \%$ to $\left.1.8 \% ; \mathrm{I}^{2}=86 \%\right)$ than in 54 open surgery cohorts $(3.8 \%, 3.1 \%$ to $4.4 \% ; I^{2}=82 \%$ ) (fig $\left.3 \Downarrow \Downarrow\right)$. The incidence of adhesive small bowel obstruction was also lower after laparoscopic surgery in 10 studies that directly compared laparoscopic and open surgery (odds ratio $0.38,95 \%$ confidence interval 0.16 to $0.91 ; \mathrm{I}^{2}=37 \%$ ).

The mean length of hospital stay for small bowel obstruction ranged from 4.4 to 13.4 days in 15 studies (table $\Downarrow$ ). In five studies included in the meta-analysis, the pooled mean length of stay was 7.8 days (95\% confidence interval 3.6 to 11.9 days; $\mathrm{I}^{2}=0 \%$ ). Pooled in-hospital mortality from small bowel obstruction, which could be derived in 19 studies, was $2.5 \%$ ( $1.9 \%$ to $\left.3.0 \% ; \mathrm{I}^{2}=58 \%\right)$. 


\section{Difficulties at reoperation}

The pooled incidence of enterotomy during repeated abdominal surgery was $3.3 \%\left(2.5 \%\right.$ to $\left.4.0 \% ; \mathrm{I}^{2}=86 \%\right)$ in 39 studies $(7654$ patients). In 16 studies ( 2565 procedures) in which the need for adhesiolysis could be confirmed, the incidence of enterotomy was $5.8 \%$ (3.7\% to $\left.7.9 \% ; \mathrm{I}^{2}=89 \%\right)$. The incidence of enterotomy seemed to depend on the type of surgery. The incidence was highest in lower gastrointestinal tract surgery $(8.7 \%, 3.8 \%$ to $\left.13.6 \% ; \mathrm{I}^{2}=84 \%\right)$, followed by gynaecological surgery $(4.8 \%$, $0.6 \%$ to $\left.9.1 \% ; \mathrm{I}^{2}=90 \%\right)$. The lowest incidence of enterotomies was found in hepatobiliary and pancreatic surgery (only laparoscopic cholecystectomy) $\left(0.4 \%, 0.0 \%\right.$ to $0.8 \%$; $\left.\mathrm{I}^{2}=84 \%\right)$ (fig $4 \Downarrow$ ).

The incidence of enterotomy was significantly lower in 30 laparoscopic cohorts $\left(1.8 \%, 1.2 \%\right.$ to $\left.2.4 \% ; \mathrm{I}^{2}=67 \%\right)$ than in eight open cohorts $\left(8.9 \%, 4.2 \%\right.$ to $\left.13.6 \% ; \mathrm{I}^{2}=95 \%\right)$. The same pattern was seen in two studies that compared laparoscopic and open surgery (odds ratio $0.21,0.05$ to $0.90 ; \mathrm{I}^{2}=0 \%$ ).

Difference in operative time was reported in 27 studies, of which 13 could be included in a meta-analysis. In 21 studies, operative time was compared between primary and repeat abdominal operation. Operative time was increased in the repeat surgery group in 15 studies and comparable in six studies. The other six studies compared repeated abdominal surgery in which an adhesion barrier had or had not been used during the preceding surgery. In five studies, a reduction of operative time was found after barrier use.

The meta-analysis including 13 studies showed that operative time increased by 15.2 minutes ( $95 \%$ confidence interval 9.3 to 21.1 minutes; $\mathrm{I}^{2}=85 \%$ ) in the repeated surgery group and varied with the anatomical location of the surgery (fig $5 \Downarrow$ ). The increase in operative time did not differ between open and laparoscopic studies.

\section{Infertility/pregnancy}

The pregnancy rate after colorectal surgery for inflammatory bowel disease was $50 \%$ ( $37 \%$ to $63 \%$; $\mathrm{I}^{2}=94 \%$ ) in 10 studies including 1004 patients attempting pregnancy, with a range in follow-up from 12 to 158 months. Nine studies compared the fertility rate in patients after the operation with that in patients before the operation or with that in patients treated medically. In all studies, the fertility rate was significantly lower in the operated group than in the non-operated group, in which the pregnancy rate was $82 \%\left(70 \%\right.$ to $\left.94 \% ; I^{2}=97 \%\right)$; the overall odds ratio was $0.15\left(0.08\right.$ to $\left.0.29 ; \mathrm{I}^{2}=82 \%\right)$ (fig $\left.6 \Downarrow\right)$. The pregnancy rate was $65 \%\left(52 \%\right.$ to $\left.78 \% ; \mathrm{I}^{2}=97 \%\right)$ in the best case scenario and $38 \%\left(23 \%\right.$ to $\left.53 \% ; \mathrm{I}^{2}=98 \%\right)$ in the worst case scenario. In three studies, $23 \%\left(18 \%\right.$ to $\left.29 \% ; \mathrm{I}^{2}=19 \%\right)$ of postoperative patients required fertility treatment.

\section{Chronic abdominal pain}

In one study following 198 patients after lower gastrointestinal tract surgery for adhesive small bowel obstruction, $40 \%$ (34\% to $47 \%$; $\mathrm{I}^{2}=$ not applicable) of patients developed chronic abdominal pain. In four studies following patients with chronic postoperative pain after previous surgery, adhesions were identified as the most likely cause of pain during diagnostic laparoscopy in $57 \%$ ( $47 \%$ to $67 \%$; $\mathrm{I}^{2}=77 \%$ ) of patients (fig $7 \Downarrow$ ).

\section{Sensitivity analyses}

Some sensitivity analyses slightly changed the point estimate, but in none of these analyses was the change clinically relevant. No other sensitivity analyses changed our results. Studies with a high risk of bias presented a significantly lower incidence of adhesive small bowel obstruction $(1.5 \%, 0.9 \%$ to $2.0 \%)$. The incidence of adhesive small bowel obstruction was comparable to the presented estimates in studies with low and intermediate risk of bias.

\section{Discussion}

The results of this study show that adhesion formation has a large negative effect on patients' health and is associated with an increased workload in clinical practice. Many patients develop an episode of small bowel obstruction or require emergency surgery with adhesiolysis for small bowel obstruction. Adhesiolysis in repeat surgery is associated with an increased incidence of inadvertent bowel injury and increases the operating time. Other sequelae of adhesion formation are decreased pregnancy rates, increased fertility treatments, and chronic abdominal pain. Considerable heterogeneity of studies was present.

\section{Strengths and limitations of study}

The major strengths of this review are the systematic approach and the large number of studies included. We have provided a comprehensive assessment of the burden of adhesions that is relevant to both clinicians and patients. The collected data present a good overview of the burden of adhesions at a population level, and the results were robust in extensive sensitivity and subgroup analyses.

Some potential limitations should be discussed. Firstly, the results should be interpreted with caution as we found considerable heterogeneity. Local variations in operative techniques, environmental factors, and the case mix seem to influence the incidence of adhesion related complication.

Secondly, publication bias cannot be excluded, as we found asymmetry in some funnel plots. Part of this asymmetry is explained by clinical heterogeneity between the patient groups included in different studies rather than by publication bias. Some asymmetry, however, is due to high incidences derived from high quality studies designed to assess incidences of small bowel obstruction or enterotomy. ${ }^{5-19}$ That is, some smaller low quality studies reporting lower incidences were possibly not identified. Our sensitivity analyses, however, showed that our results were quite robust, so we do not expect that these smaller low quality studies would change our results.

Thirdly, we excluded studies done before 1990, which might have introduced bias. We believe, however, that studies done before 1990 would not provide an estimate that is generalisable to current practice because of the broad introduction of laparoscopy in general surgery at that time and the increased use of tissue sparing techniques and instruments at the end of the 20th century. Furthermore, sensitivity analyses did not show relevant differences between the period before and after 2000, suggesting that we could combine the data from the studies of the past two decades to provide a more precise estimate.

Fourthly, about $4 \%$ of papers could not be retrieved. We tried to retrieve these papers by contacting editors, authors, and other libraries in the Netherlands and abroad. The studies that could not be retrieved were small case series. The robustness of our sensitivity analyses shows that that these small case series would be unlikely to have changed our results.

Fifthly, costs and quality of life implications are not included in our analyses as these were either not reported at all or reported in such a heterogeneous way that pooling was not possible. On the basis of the high incidences of adhesion related 
complications, adhesions might affect the quality of life in many patients and cause a significant economic burden.

\section{Comparison with other studies}

The landmark publications of the SCAR Group were the first to consider the effect of postoperative adhesion formation in a large population. ${ }^{4-16}$ In the SCAR studies, readmissions (defined by identification and diagnostic codes) were used as a proxy for the effect of adhesions. Incidence of adhesions will be difficult to confirm using these diagnostic codes. In the SCAR studies, many readmissions were classified as possibly related to adhesions that could not directly be linked to adhesions. Our study is unique in presenting distinct complications from adhesions as outcomes. Such outcomes are more interpretable for clinicians and patients. Additionally, the large number of studies included in our analysis represented a fivefold higher number of patients than in the SCAR studies, and our results are more complete in analysing adhesion related complications, such as infertility and chronic pain, which in general do not require readmission.

The differences in incidences between laparoscopy and open surgery in this review are in agreement with an earlier study from our group, which showed small benefits of laparoscopy on adhesion related outcomes. ${ }^{20}$ The results of this study contribute to the existing evidence that laparoscopy reduces the incidence of adhesion related complications. Notably, laparoscopy does not totally prevent adhesion formation, contradicting the opinion that the use of anti-adhesive barriers is not needed in laparoscopy. ${ }^{7}$

\section{Implications for clinical practice}

We have shown that postsurgical adhesion formation has an important risk for morbidity. The complications related to adhesions are diverse in nature and clinical consequences, varying from emergency reoperations for small bowel obstruction to fertility treatments. Informing patients about these risks before abdominal surgery is imperative. Failure to do so could result in medicolegal claims. ${ }^{21}$ However, less than $10 \%$ of surgeons and gynaecologists routinely inform their patients of the risks of adhesions. ${ }^{79}$

This study provides important data for the development of guidelines for prevention of adhesions. So far, guidelines are present only in gynaecology, which comprises a minority of adhesion related problems in comparison with general surgery, particularly gastrointestinal and paediatric surgery. ${ }^{22}$ Our review shows important relations between type of surgery and incidence of adhesion related complications. Evidence shows that adhesion barriers effectively reduce adhesion formation in high risk surgery. ${ }^{13-24}$ The detailed knowledge of the disease burden of adhesions now available may be used to power future trials of anti-adhesive barriers preventing clinically relevant outcomes of adhesions.

\section{Conclusions}

This review provides detailed and systematically analysed knowledge of the large disease burden of adhesions. Complications of postoperative adhesion formation are frequent, have a large negative effect on patients' health, and increase workload in clinical practice. Many patients develop an episode of small bowel obstruction or an inadvertent bowel injury due to adhesiolysis. The quantitative effects should be interpreted with caution owing to large heterogeneity.
We thank I Gerych, General Surgery Department, Danylo Halytsky Lviv National Medical University, Ukraine, for his help in translating articles written in Russian.

Contributors: RPGtB was involved in study design and design of data collection tools, collected and analysed data, and drafted the article. YI collected and analysed data and critically reviewed the article. EJPvS, NDB, FPMK, JJ, and EB were involved in study design and critically reviewed the article. MMR was involved in study design, critically revised the review protocol, and critically reviewed the article. HvG was involved in study design, supervised data collection, and critically reviewed the article. All authors gave final approval of the article. RPGtB and HvG are the guarantors.

Funding: No external funding has been obtained for this research.

Competing interests: All authors have completed the ICMJE uniform disclosure form at www.icmje.org/coi_disclosure.pdf (available on request from the corresponding author) and declare: no support from any organisation for the submitted work; no financial relationships with any organisations that might have an interest in the submitted work in the previous three years; no other relationships or activities that could appear to have influenced the submitted work.

Ethical approval: Not needed.

Data sharing: Technical appendix, statistical code, and dataset are available from the corresponding author at richard_tenbroek@hotmail.com.

1 Van Goor H. Consequences and complications of peritoneal adhesions. Colorectal Dis 2007;9(suppl 2):25-34.

2 Taylor GW, Jayne DG, Brown SR, Thorpe H, Brown JM, Dewberry SC, et al. Adhesions and incisional hernias following laparoscopic versus open surgery for colorectal cancer in the CLASICC trial. Br J Surg 2010;97:70-8.

3 Nieuwenhuijzen M, Reijnen MMPJ, Kuijpers JHC, van Goor H. Small bowel obstruction after total or subtotal colectomy: a 10-year retrospective review. Br J Surg 1998;85:1242-5.

4 Ellis H, Moran BJ, Thompson JN, Parker MC, Wilson MS, Menzies D, et al. Adhesion-related hospital readmissions after abdominal and pelvic surgery: a retrospective cohort study. Lancet 1999;353:1476-80.

5 Ten Broek RP, Strik C, Issa Y, Bleichrodt RP, van Goor H. Adhesiolysis-related morbidity in abdominal surgery. Ann Surg 2013;258:98-106.

6 Ording Olsen K, Juul S, Berndtsson I, Oresland T, Laurberg S. Ulcerative colitis: female fecundity before diagnosis, during disease, and after surgery compared with a population sample. Gastroenterology 2002;122:15-9.

7 Schreinemacher MH, Ten Broek RP, Bakkum EA, van Goor H, Bouvy ND. Adhesion awareness: a national survey of surgeons. World J Surg 2010;34:2805-12.

8 Parker MC, Wilson MS, van Goor H, Moran BJ, Jeekel J, Duron JJ, et al. Adhesions and colorectal surgery—call for action. Colorectal Dis 2007;9(suppl 2):66-72.

9 Trew G, Cooke ID, Lower AM, McVeigh E. Post-operative abdominal adhesions-awareness of UK gynaecologists-a survey of members of the Royal College of Obstetricians and Gynaecologists. Gynecol Surg 2009;6:25-37.

10 Parikh JA, Ko CY, Maggard MA, Zingmond DS. What is the rate of small bowel obstruction after colectomy? Am Surg 2008;74:1001-5.

11 Ng SS, Leung KL, Lee JF, Yiu RY, Li JC, Hon SS. Long-term morbidity and oncologic outcomes of laparoscopic-assisted anterior resection for upper rectal cancer: ten-year results of a prospective, randomized trial. Dis Colon Rectum 2009;52:558-66.

12 Leung TT, Dixon E, Gill M, Mador BD, Moulton KM, Kaplan GG, et al. Bowel obstruction following appendectomy: what is the true incidence? Ann Surg 2009;250:51-3.

13 Ahmad G, Duffy JM, Farquhar C, Vail A, Vandekerckhove P, Watson A, et al. Barrier agents for adhesion prevention after gynaecological surgery. Cochrane Database Syst Rev 2008;(2):CD000475

14 Van Der Krabben AA, Dijkstra FR, Nieuwenhuijzen M, Reijnen MMPJ, Schaapveld M, van Goor $\mathrm{H}$. Morbidity and mortality of inadvertent enterotomy during adhesiotomy. $\mathrm{Br} \mathrm{J}$ Surg 2000;87:467-71.

15 Parker MC, Ellis H, Moran BJ, Thompson JN, Wilson MS, Menzies D, et al. Postoperative adhesions: ten-year follow-up of 12,584 patients undergoing lower abdominal surgery. Dis Colon Rectum 2001;44:822-9.

16 Lower AM, Hawthorn RJ, Clark D, Boyd JH, Finlayson AR, Knight AD, et al. Adhesion-related readmissions following gynaecological laparoscopy or laparotomy in Scotland: an epidemiological study of 24046 patients. Hum Reprod 2004; 19:1877-85.

17 Higgins J, Green S. Cochrane handbook for systematic reviews of interventions. Version 5.1.0. Cochrane Collaboration, 2011.

18 MacLean AR, Cohen Z, MacRae HM, O'Connor BI, Mukraj D, Kennedy ED, et al. Risk of small bowel obstruction after the ileal pouch-anal anastomosis. Ann Surg 2002;235:200-6.

19 Beck DE, Opelka FG, Bailey HR, Rauh SM, Pashos CL. Incidence of small-bowel obstruction and adhesiolysis after open colorectal and general surgery. Dis Colon Rectum 1999;42:241-8.

20 Ten Broek RP, Kok-Krant N, Bakkum EA, Bleichrodt RP, van Goor H. Different surgical techniques to reduce post-operative adhesion formation: a systematic review and meta-analysis. Hum Reprod Update 2013;19:12-25.

21 Ellis H. Medicolegal consequences of adhesions. Hosp Med 2004;65:348-350.

22 De Wilde RL, Brolmann H, Koninckx PR, Lundorff P, Lower AM, Wattiez A, et al. Prevention of adhesions in gynaecological surgery: the 2012 European field guideline. Gynecol Surg 2012;9:365-8. 


\section{What is already known on this topic}

Adhesion formation is a common cause of long term complications following abdominal or pelvic surgery

Adhesion related complications comprise various clinical entities including small bowel obstruction, female infertility, difficulties at reoperation, and chronic pain

The incidence and effect of adhesion related complications are not precisely known

\section{What this study adds}

Detailed and systematically analysed knowledge of the large disease burden of adhesions is now available

This knowledge may be used for better preoperative patient counselling and operative management and to power future trials of anti-adhesive barriers

Studies on adhesion formation and its clinical consequences are heterogeneous

23 Kumar S, Wong PF, Leaper DJ. Intra-peritoneal prophylactic agents for preventing adhesions and adhesive intestinal obstruction after non-gynaecological abdominal surgery. Cochrane Database Syst Rev 2009;(1):CD005080.

24 Fazio VW, Cohen Z, Fleshman JW, Van GH, Bauer JJ, Wolff BG, et al. Reduction in adhesive small-bowel obstruction by Seprafilm adhesion barrier after intestinal resection. Dis Colon Rectum 2006;49:1-11.

Accepted: 20 August 2013

\section{Cite this as: BMJ 2013;347:f5588}

This is an Open Access article distributed in accordance with the Creative Commons Attribution Non Commercial (CC BY-NC 3.0) license, which permits others to distribute, remix, adapt, build upon this work non-commercially, and license their derivative works on different terms, provided the original work is properly cited and the use is non-commercial. See: http://creativecommons.org/licenses/by-nc/3.0/. 


\section{Table}

Table 1| Qualitative analysis of length of hospital stay for treatment of adhesive small bowel obstruction. Values are mean (SD) unless stated otherwise

\begin{tabular}{|c|c|c|c|c|c|c|}
\hline \multirow[b]{2}{*}{ Study } & \multicolumn{2}{|c|}{ Total group } & \multicolumn{2}{|c|}{ Conservative treatment } & \multicolumn{2}{|c|}{ Operative treatment } \\
\hline & No & Length of stay & No & Length of stay & No & Length of stay \\
\hline Alwan 1999 & 332 & $8(0-156)^{\star}$ & - & - & - & - \\
\hline Beyrout 2006 & 258 & $7(1-63) \dagger$ & - & - & - & - \\
\hline Borzellino 2004 & 65 & $4.4(1-22) \dagger$ & - & - & 65 & $4.4(1-22) \dagger$ \\
\hline Kawamura 2010 & 10 & $11.4(7.4)$ & 7 & $11.1(8.9)$ & 3 & $12.0(1.7)$ \\
\hline Khaikin 2007 & 72 & 7-13‡ & - & - & 72 & 7-13‡ \\
\hline Kössi 2004 & 123 & $7(0.6)$ & - & - & - & - \\
\hline Menzies 2001 & 110 & $10.5(1-45) \dagger$ & 69 & $7(1-23) \dagger$ & 41 & $16.3(2-45) \dagger$ \\
\hline Miller 2002 & - & - & 23 & $6(2-33)^{\star}$ & 7 & $12(9-17)^{\star}$ \\
\hline Miller 2000 & - & - & 267 & $4(\mathrm{NA})^{*}$ & 143 & $12(\mathrm{NA})^{*}$ \\
\hline Parikh 2008 & 4555 & 10.6 (NA) & 3429 & $9.5(\mathrm{NA})$ & 1126 & $14(\mathrm{NA})$ \\
\hline Rosin 2000 & 21 & $6.9(5.1)$ & - & - & 21 & $6.9(5.1)$ \\
\hline Shih 2003 & 293 & $6.5(3.0)$ & 220 & $6.9(2.9)$ & 73 & $5.9(2.8)$ \\
\hline Sosa 1993 & 116 & $13.4(2-\mathrm{NA}) \dagger$ & 95 & $13.7(2-\mathrm{NA}) \dagger$ & 21 & $12.3(6-48) \dagger$ \\
\hline Suzuki 2003 & 17 & $9.9(4.4)$ & - & - & - & - \\
\hline Wang 2009 & 46 & $8.8(6-20) \dagger$ & - & - & - & - \\
\hline
\end{tabular}

$\mathrm{NA}=$ not available.

*Median (range).

†Mean (range); used only for articles that provided insufficient data to extract mean and SD or median and range.

¥Median length of stay 7 in 31 patients receiving laparoscopic surgery, 8 in 10 patients after conversion, and 13 in 31 patients receiving open surgery. 


\section{Figures}

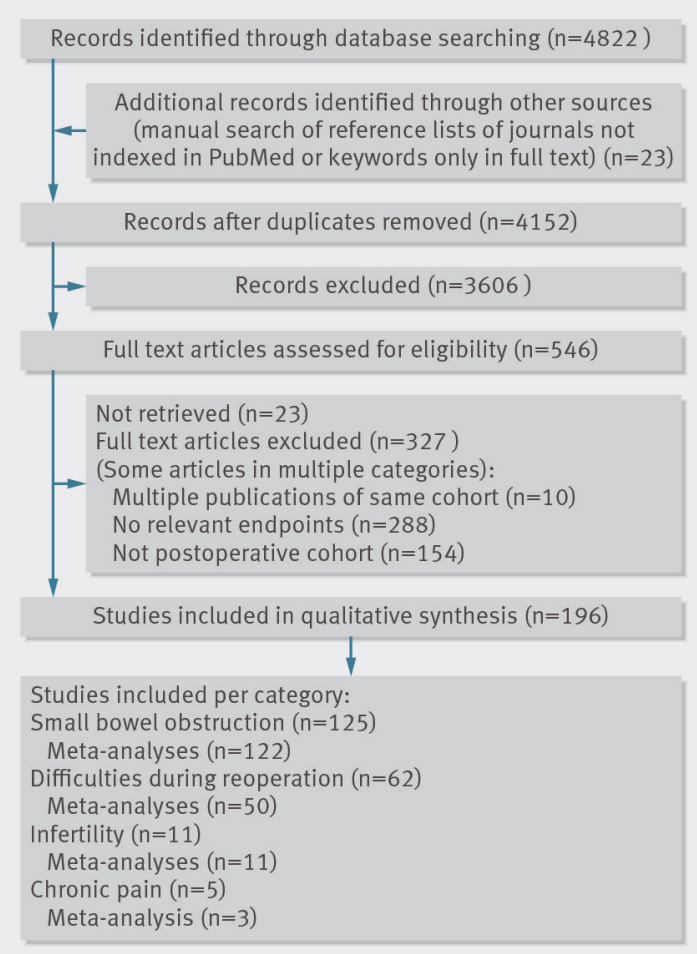

Fig 1 PRISMA flow chart 


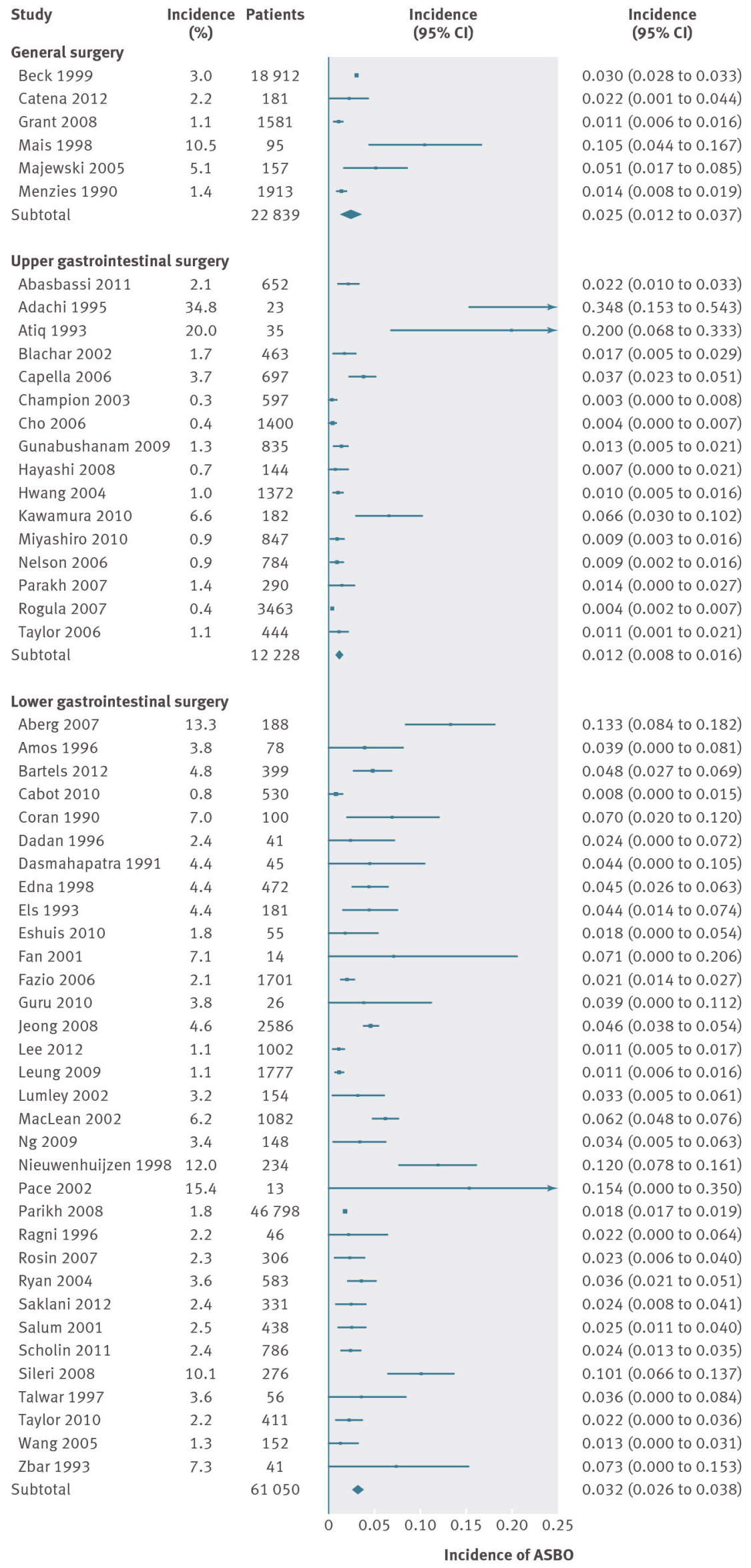

Fig 2 Forest plot of incidence of adhesive small bowel obstruction (ASBO), stratified by anatomical location 


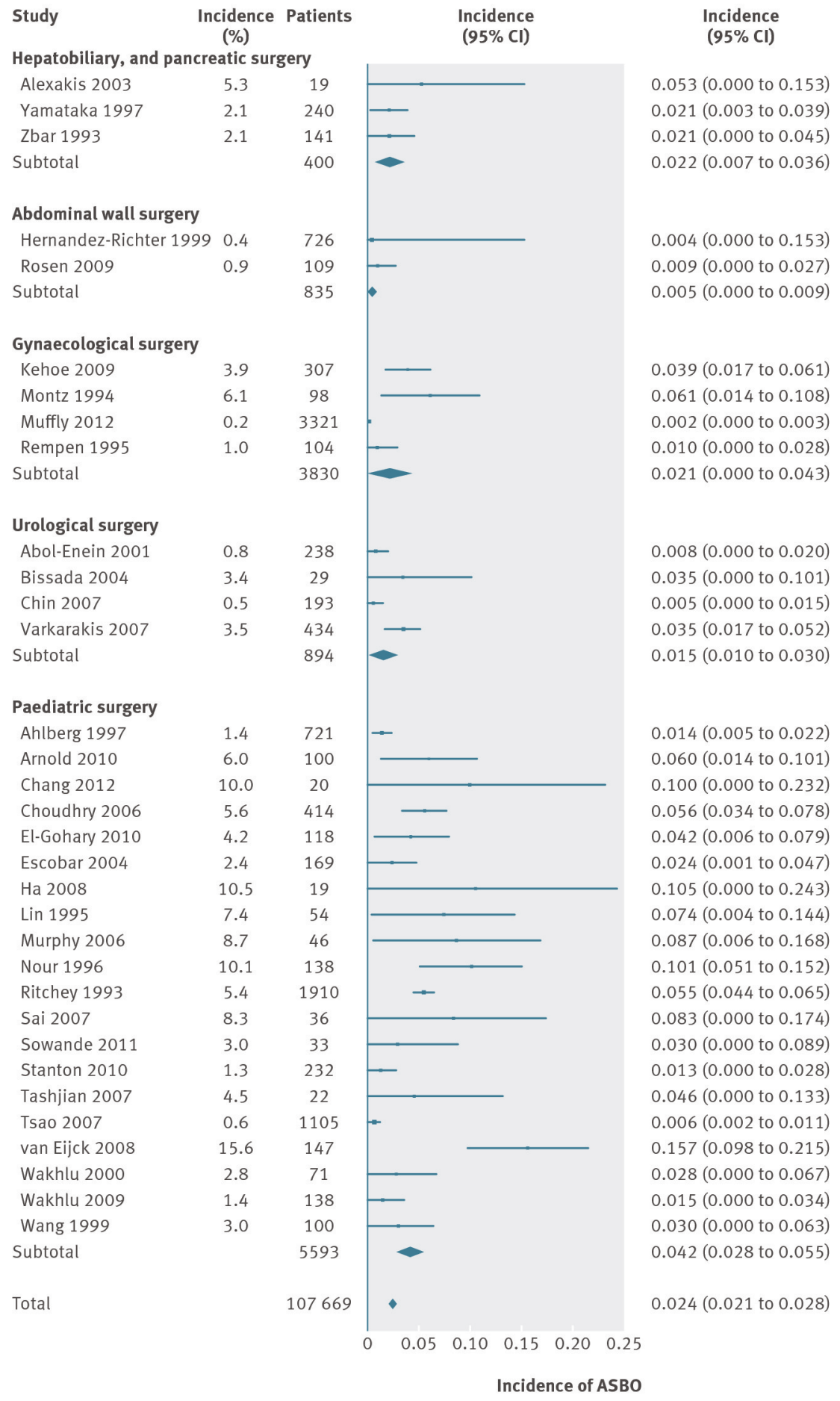

Fig 2 Forest plot of incidence of adhesive small bowel obstruction (ASBO), stratified by anatomical location (continued) 


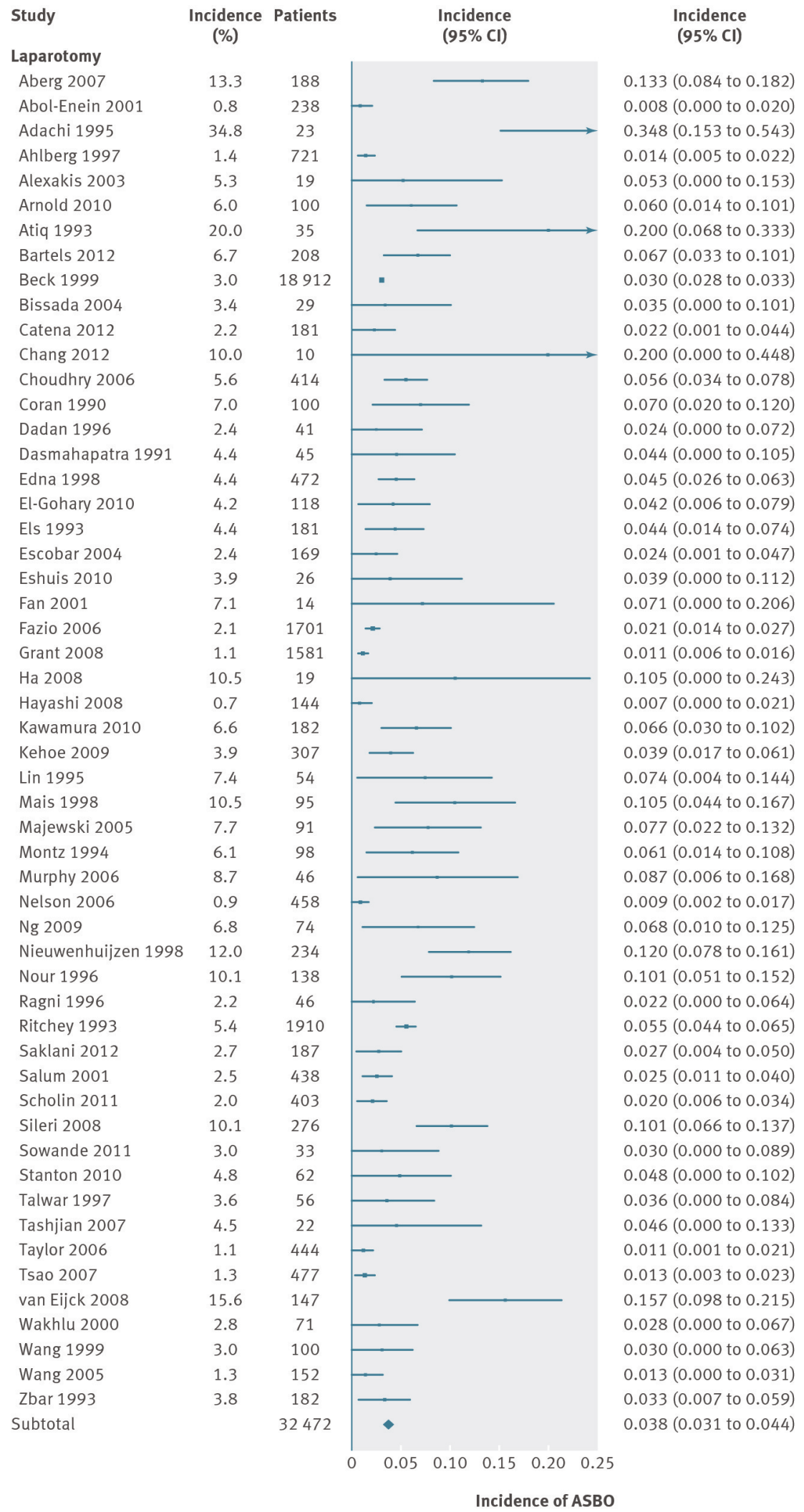

Fig 3 Forest plot of incidence of adhesive small bowel obstruction (ASBO), stratified by laparoscopy and laparotomy 


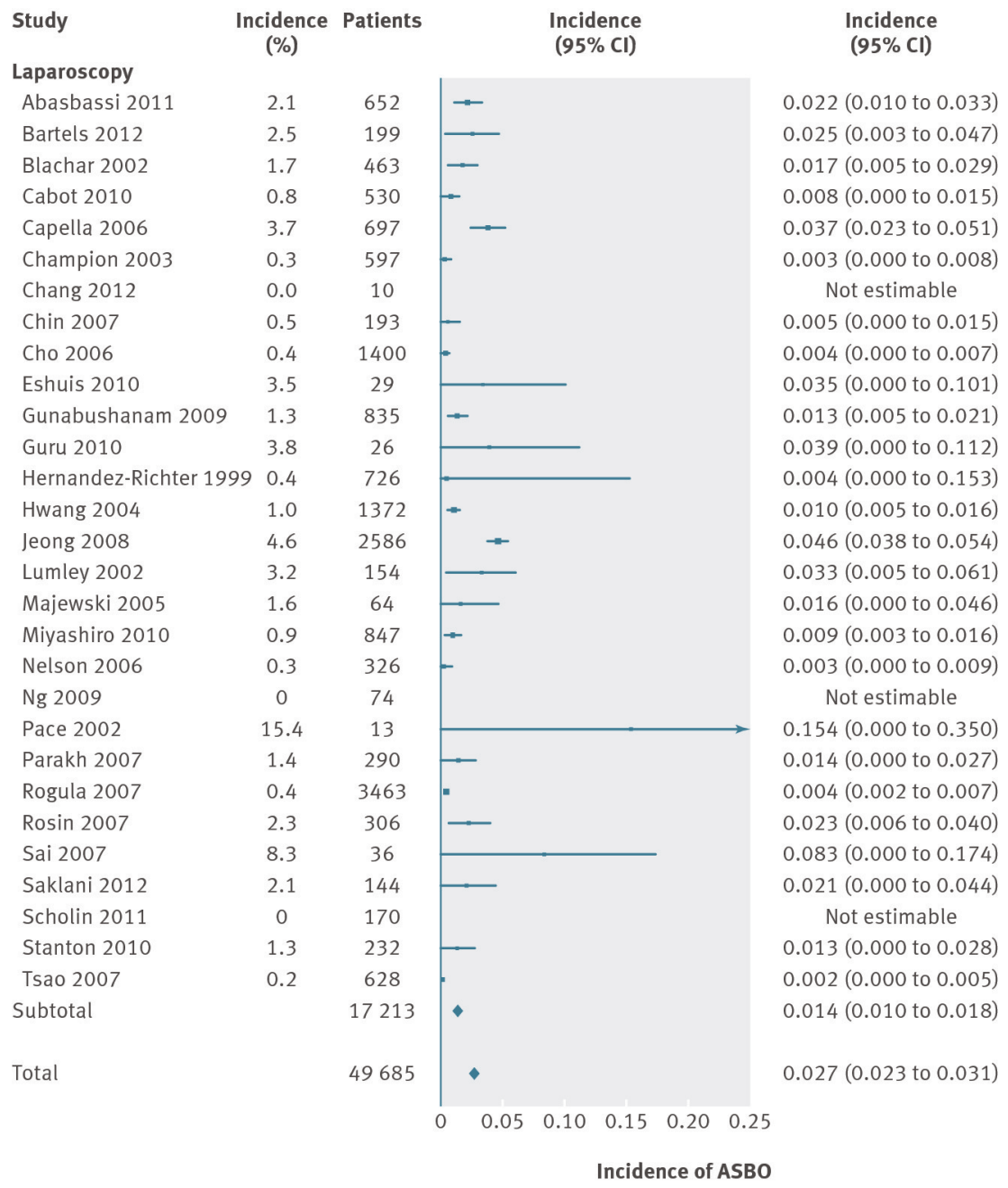

Fig 3 Forest plot of incidence of adhesive small bowel obstruction (ASBO), stratified by laparoscopy and laparotomy (continued) 


\begin{tabular}{|c|c|c|c|c|c|c|}
\hline Study & $\begin{array}{c}\text { Incidence } \\
(\%)\end{array}$ & Patients & \multicolumn{3}{|c|}{$\begin{array}{c}\text { Incidence } \\
(95 \% \mathrm{CI})\end{array}$} & $\begin{array}{l}\text { Incidence } \\
(95 \% \mathrm{CI})\end{array}$ \\
\hline \multicolumn{7}{|l|}{ General surgery } \\
\hline Borzellino 2004 & 4.6 & 65 & & & & $0.046(0.000$ to 0.097$)$ \\
\hline Burcos 2002 & 0.4 & 452 & - & & & $0.004(0.000$ to 0.011$)$ \\
\hline Chopra 2003 & 14.7 & 75 & & & & $0.147(0.067$ to 0.227$)$ \\
\hline Fevang 2004 & 6.0 & 563 & $\longrightarrow$ & & & $0.060(0.041$ to 0.080$)$ \\
\hline Francois 1994 & 9.6 & 52 & & & & $0.096(0.016$ to 0.176$)$ \\
\hline Freys 1994 & 0.8 & 240 & - & & & $0.008(0.000$ to 0.020$)$ \\
\hline Johanet 1999 & 2.9 & 276 & $\longrightarrow$ & & & $0.029(0.009$ to 0.049$)$ \\
\hline Parent 1995 & 9.7 & 31 & & & & $0.097(0.000$ to 0.201$)$ \\
\hline Sato 2001 & 5.9 & 17 & & & & $0.059(0.000$ to 0.171$)$ \\
\hline Ten Broek 2012 & 10.0 & 502 & & 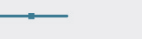 & & $0.100(0.073$ to 0.126$)$ \\
\hline Subtotal & & 2273 & - & & & $0.052(0.028$ to 0.076$)$ \\
\hline \multicolumn{7}{|c|}{ Lower gastrointestinal surgery } \\
\hline Alwan 1999 & 4.0 & 253 & $\longrightarrow$ & & & $0.040(0.016$ to 0.064$)$ \\
\hline Kawamura 2009 & 2.8 & 36 & & & & $0.028(0.000$ to 0.082$)$ \\
\hline Keck 1994 & 16.0 & 50 & & & 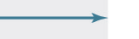 & $0.160(0.058$ to 0.261$)$ \\
\hline Naguib 2012 & 2.9 & 68 & & & & $0.029(0.000$ to 0.070$)$ \\
\hline Oliveira 1997 & 14.3 & 14 & & & & $0.143(0.000$ to 0.326$)$ \\
\hline Petersen 2009 & 5.6 & 71 & & & & $0.056(0.003$ to 0.110$)$ \\
\hline Shayani 2002 & 15.0 & 20 & & & & $0.150(0.000$ to 0.307$)$ \\
\hline Van Der Krabben 2000 & O 19.3 & 270 & & & & $0.193(0.146$ to 0.240$)$ \\
\hline Subtotal & & 782 & & - & & $0.087(0.038$ to 0.136$)$ \\
\hline \multicolumn{7}{|c|}{ Hepatobiliary, and pancreatic surgery } \\
\hline Bouasker 2010 & 1.3 & 233 & 5 & & & $0.013(0.000$ to 0.027$)$ \\
\hline Ercan 2009 & 0.3 & 677 & - & & & $0.003(0.000$ to 0.007$)$ \\
\hline Fuchs 1992 & 0.6 & 170 & - & & & $0.006(0.000$ to 0.017$)$ \\
\hline Subtotal & & 1080 & $\leftrightarrow$ & & & $0.004(0.000$ to 0.008$)$ \\
\hline \multicolumn{7}{|l|}{ Abdominal wall surgery } \\
\hline Baccari 2009 & 2.5 & 200 & - & & & $0.025(0.003$ to 0.047$)$ \\
\hline Baghai 2009 & 20.0 & 10 & & & & $0.200(0.000$ to 0.448$)$ \\
\hline Ben-Haim 2002 & 6.0 & 100 & & - & & $0.060(0.014$ to 0.107$)$ \\
\hline Ferrari 2008 & 1.0 & 100 & + & & & $0.010(0.000$ to 0.030$)$ \\
\hline Kirshtein 2002 & 1.9 & 103 & & & & $0.019(0.000$ to 0.046$)$ \\
\hline Kyzer 1999 & 3.8 & 53 & & & & 0.038 (0.000 to 0.089$)$ \\
\hline LeBlanc 2003 & 1.0 & 200 & - & & & $0.010(0.000$ to 0.024$)$ \\
\hline Perrone 2005 & 3.3 & 121 & & & & $0.033(0.001$ to 0.065$)$ \\
\hline Varnell 2008 & 2.1 & 47 & & & & 0.021 (0.000 to 0.063$)$ \\
\hline Subtotal & & 934 & $\bullet$ & & & 0.019 (0.010 to 0.029$)$ \\
\hline \multicolumn{7}{|l|}{ Gynaecological surgery } \\
\hline Boukerrou 2001 & 6.3 & 16 & & & & $0.063(0.000$ to 0.181$)$ \\
\hline Finan 1997 & 7.4 & 27 & & & & $0.074(0.000$ to 0.173$)$ \\
\hline Husain 2001 & 2.0 & 150 & 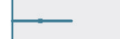 & & & $0.020(0.000$ to 0.042$)$ \\
\hline Kolmorgen 1998 & 0.5 & 789 & - & & & $0.005(0.000$ to 0.010$)$ \\
\hline Kumakiri 2010 & 11.4 & 307 & & & & $0.114(0.079$ to 0.150$)$ \\
\hline Subtotal & & 1289 & $\longrightarrow$ & & & $0.048(0.006$ to 0.091$)$ \\
\hline \multicolumn{7}{|l|}{ Urological surgery } \\
\hline Petros 2011 & 2.4 & 41 & & & & 0.024 (0.000 to 0.072$)$ \\
\hline Siddiqui 2010 & 0.3 & 1049 & - & & & $0.003(0.000$ to 0.006$)$ \\
\hline Subtotal & & 1090 & 6 & & & $0.003(0.000$ to 0.006$)$ \\
\hline \multicolumn{7}{|l|}{ Paediatric surgery } \\
\hline Akgur 1991 & 4.2 & 120 & & & & 0.042 (0.006 to 0.078$)$ \\
\hline Becmeur 1998 & 5.8 & 86 & & & & $0.058(0.009$ to 0.108$)$ \\
\hline Subtotal & & 206 & $\longrightarrow$ & & & $0.047(0.018$ to 0.076$)$ \\
\hline \multirow[t]{2}{*}{ Total } & & 7654 & $\bullet$ & & & $0.033(0.025$ to 0.040$)$ \\
\hline & & & 0.05 & $0.10 \quad 0.15$ & $0.20 \quad 0.25$ & \\
\hline
\end{tabular}

Fig 4 Forest plot of incidence of enterotomy, stratified by anatomical location 


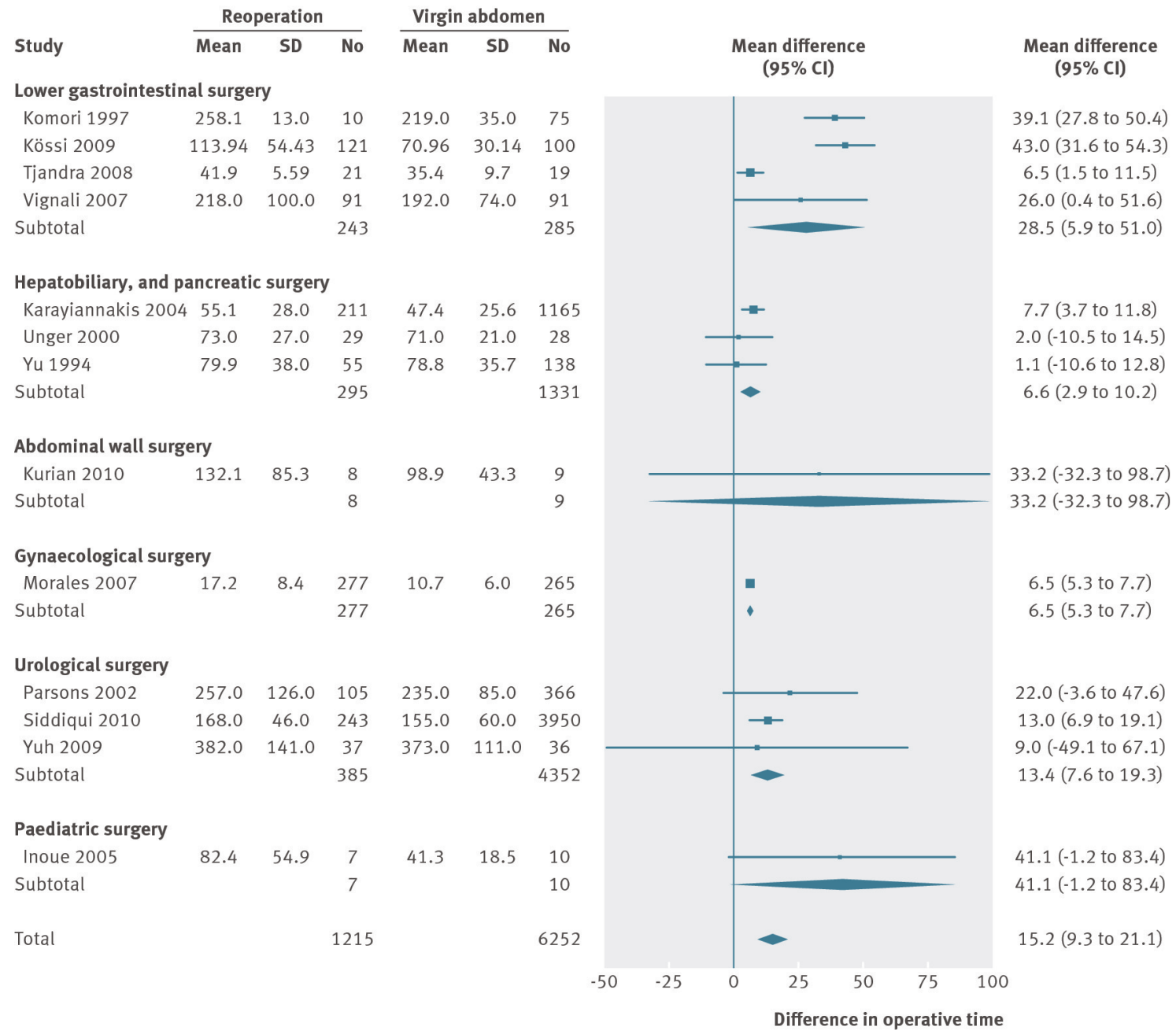

Fig 5 Forest plot of operative time, stratified by anatomical location

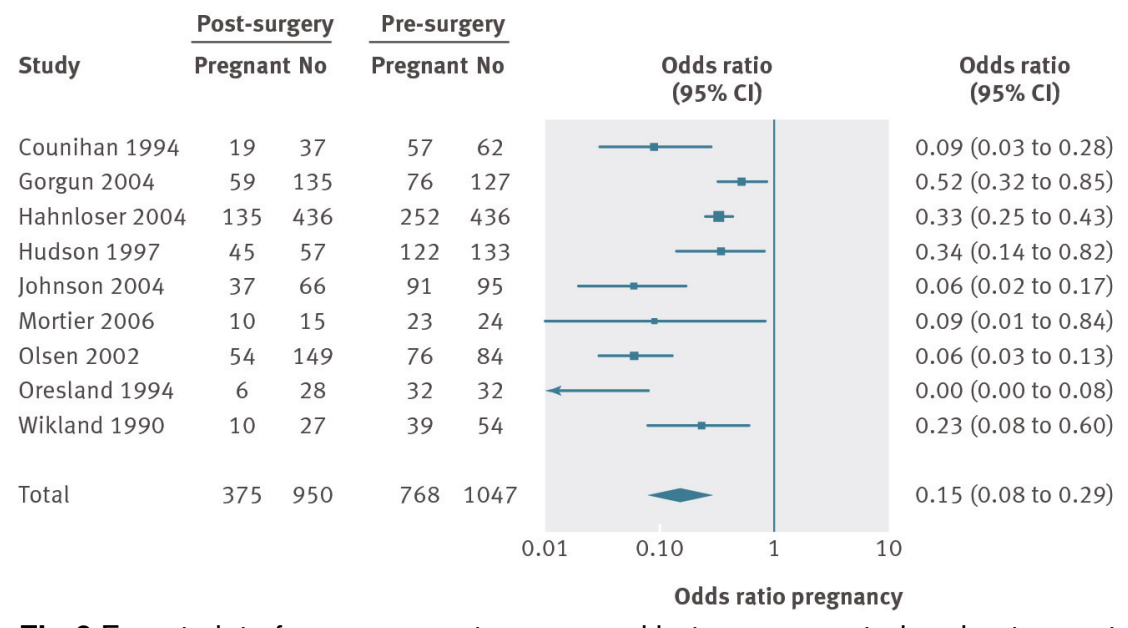

Fig 6 Forest plot of pregnancy rate compared between operated and not operated patients 


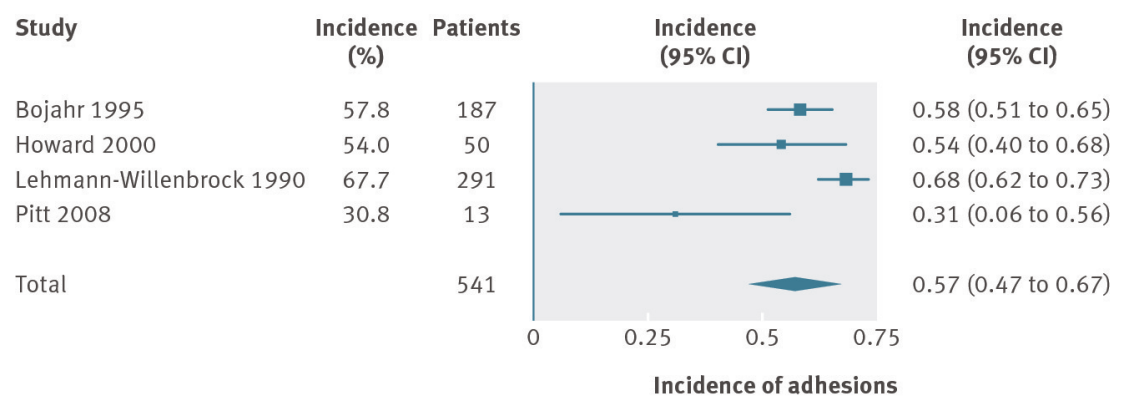

Fig 7 Forest plot of incidence of adhesions in patients with chronic postoperative pain, including all studies 